Case Reports
in Dermatology
Case Rep Dermatol 2021;13:154-163

DOI: 10.1159/000513469

Published online: March 3, 2021

(C) 2021 The Author(s)

Published by S. Karger AG, Basel

www.karger.com/cde

This article is licensed under the Creative Commons Attribution-NonCommercial 4.0 International License (CC BY-NC) (http://www.karger.com/Services/OpenAccessLicense). Usage and distribution for commercial purposes requires written permission.

\title{
Severe Generalized Bullous Fixed Drug Eruption Treated with Cyclosporine: A Case Report and Literature Review
}

\author{
Hailey C. Barootes ${ }^{a} \quad$ Erin R. Peebles ${ }^{a} \quad$ Doreen Matsui $^{a} \quad$ Michael Rieder $^{b}$ \\ ${\text { Awatif Abuzgaiab }{ }^{\mathrm{b}} \text { Javed A. Mohammed }}^{\mathrm{a}}$ \\ aDepartment of Paediatrics, Children's Hospital, London Health Sciences Centre, Western \\ University, London, ON, Canada; ${ }^{b}$ Department of Paediatrics, Division of Paediatric \\ Clinical Pharmacology, Children's Hospital, London Health Sciences Centre, Robarts \\ Research Institute, Western University, London, ON, Canada
}

\section{Keywords}

Drug reaction · Pharmacology · Systemic therapy

\begin{abstract}
Generalized bullous fixed drug eruptions (GBFDEs) are rare in the paediatric population. We present the case of a 7-year-old girl with GBFDE believed to be secondary to oral ibuprofen, who experienced rapid resolution of lesions and cessation of blistering with a 3-week course of oral cyclosporine. To the best of our knowledge, this is the first report of a paediatric case of GBFDE treated with cyclosporine. In our report, we review published cases of GBFDE in children, and all adult cases managed with cyclosporine.

(C) 2021 The Author(s)

Published by S. Karger AG, Basel
\end{abstract}

Javed A. Mohammed
Department of Paediatrics, Paediatric Dermatology, Children's Hospital
London Health Sciences Centre, Nixon Medical Centre
510 Southdale Rd. E., Suite 301, London, ON N6E 0B2 (Canada)
Javed.Mohammed@lhsc.on.ca




\section{Case Reports in Dermatology}

Case Rep Dermatol 2021;13:154-163

DOI: 10.1159/000513469

(C) 2021 The Author(s). Published by S. Karger AG, Basel www.karger.com/cde

Barootes et al.: Fixed Drug Eruption Treated with Cyclosporine

\section{Introduction}

Fixed drug eruptions (FDEs) are thought to account for between 14 and $22 \%$ of cutaneous drug eruptions in children $[1,2]$. They are characterized by the development of one or more well-circumscribed annular or oval erythematous patches and plaques that appear following systemic exposure to a drug. Upon discontinuation of the offending drug, the lesions typically resolve with postinflammatory hyperpigmentation and recur at the same sites with repeated drug exposure [3].

Generalized bullous is a rare subtype of FDE, described as the classic well-demarcated FDE lesions involving at least $10 \%$ of the body surface area with superimposed bullae. Often, lesions are distributed on at least three of six different anatomic sites including the head and neck, anterior trunk, posterior trunk, upper extremities, lower extremities, and genitalia [4]. In reviewing the literature, there are very few published cases of generalized bullous FDEs (GBFDEs) in the paediatric population [5-9]. However, their extensive distribution and skin detachment warrants urgent assessment and management.

Optimal treatment of GBFDE is not yet established due to its rarity, the paucity of evidence, and our lack of mechanistic understanding of the pathophysiology. Current management includes immediate cessation of the offending drug and supportive therapy with antihistamines, analgesics, or topical corticosteroids. Due to the severity of the eruption, systemic treatment is not uncommonly required. The literature suggests a potential response to systemic therapies including intravenous steroids and immunoglobulin [10]. Five cases of GBFDE in adult patients also demonstrate a benefit from systemic cyclosporine [11-14].

In this report, we present a case of severe GBFDE in a child, and to the best of our knowledge, the first reported paediatric case to be managed with systemic cyclosporine.

\section{Case Presentation}

A 7-year-old, previously healthy female presented to the paediatric emergency department with a 6-h history of a rapid-onset, pruritic rash. The rash presented as round erythematous lesions on her posterior trunk, upper and lower extremities, and neck and face, as well as diffuse erythema on her anterior thorax. Approximately $3 \mathrm{~h}$ later, several painful blisters had developed on her right anterior thorax. Of note, the patient had a 4-day history of cough, congestion, and fever prior to rash development that was treated with both oral ibuprofen $\left(\right.$ Advil $\left.^{\circledR}\right)$ and acetaminophen $\left(\right.$ Tylenol $\left.^{\circledR}\right)$.

The parents reported that the patient had experienced a similar, but less severe, rash on four previous occasions. Each time, she had developed oval erythematous-to-brown patches on her trunk and extremities, which resolved with hyperpigmentation. Each successive eruption had occurred in the same locations but had become more severe with new areas of involvement. When the generalized eruption occurred, the previously affected, oval-shaped areas from the prior episodes became erythematous again. It was reported by her parents that liquid Advil ${ }^{\circledR}$ had been administered prior to all eruptions. However, the parents could not remember if one of the episodes had been preceded by liquid Tylenol ${ }^{\circledR}$ only or both Advil ${ }^{\circledR}$ 


\section{Case Reports in Dermatology}

Case Rep Dermatol 2021;13:154-163

DOI: 10.1159/000513469

(C) 2021 The Author(s). Published by S. Karger AG, Basel www.karger.com/cde

Barootes et al.: Fixed Drug Eruption Treated with Cyclosporine

and Tylenol ${ }^{\circledR}$. Of note, the patient was fully immunized with no known allergies and a noncontributory personal and family history.

On examination, the patient was febrile but clinically stable. She had multiple large round erythematous-to-violaceous patches and plaques on her posterior trunk, with smaller lesions on her upper and lower extremities. Her palms, soles, and genital region were spared. She had multiple similar plaques on her lower abdomen with diffuse erythema overlying her anterior thorax. She also had a large bulla with several surrounding vesicles on her right abdomen (Fig. 1). Nikolsky's sign was negative. There was no mucous membrane involvement except erythema of the posterior pharynx. Full body skin examination was otherwise unremarkable.

In the emergency department, the patient received a normal saline bolus for tachycardia and 1 dose of $1 \mathrm{mg} / \mathrm{kg}$ of prednisone orally, prior to consultation with paediatric dermatology. Bloodwork including a complete blood count and liver and renal function tests were all within normal limits except for an elevated C-reactive protein of $76.2 \mathrm{mg} / \mathrm{L}$. A viral nasopharyngeal swab was positive for adenovirus.

Paediatric dermatology was consulted, and a diagnosis of severe GBFDE was made. Due to the severity and extent of the reaction, covering $28 \%$ of the patient's body surface area, prednisone was discontinued (1 dose was received) and oral cyclosporine was commenced at $5 \mathrm{mg} / \mathrm{kg} /$ day divided into 2 daily doses for 1 week, following normal screening bloodwork. Cyclosporine resulted in a significant reduction of erythema within $24 \mathrm{~h}$, with no further progression of blistering. After 1 week, the dose was weaned to $2.5 \mathrm{mg} / \mathrm{kg} /$ day for a total of 2 weeks. Cyclosporine was then stopped, as the patient's lesions had resolved with postinflammatory hyperpigmentation, which eventually faded (Fig. 2). Cyclosporine was tolerated well with no side effects.

As the putative mechanism of GBFDE is T-cell driven, an in vitro lymphocyte toxicity assay specifically evaluating T-cell toxicity was performed. This assay, which has been used to explore the pathophysiology of hypersensitivity adverse drug reactions such as drug-induced serum sickness-like reactions, is a model system in which the patient's lymphocytes are incubated with the drug in question in the presence and absence of murine microsomes to simulate drug metabolism. The viability of the patient's cells is compared to the viability of the cells of controls, including healthy volunteers and drug-tolerant patients. These studies have established the importance of reactive drug metabolites as a critical first step in the pathogenesis of several important classes of drug hypersensitivity. In the case of this patient, we demonstrated a significant dose-related increase in cellular toxicity determined by MTT dye conversion when peripheral white blood cells of the patient were incubated with analytical-grade ibuprofen versus the cells of a control volunteer similarly incubated with ibuprofen (at 125 $\mu \mathrm{M}$ ibuprofen, patient cell viability of $10 \pm 4 \%$ vs. control cell viability of $77 \pm 5 \%$; $p<0.05$ ). Toxicity testing with acetaminophen, in contrast, produced no changes in cell viability when the cells of the patient were incubated with increasing concentrations of acetaminophen compared to the cells of controls. This testing supported the clinical history and our hypothesis that ibuprofen was the culprit drug, and suggested that neither acetaminophen nor the components of the liquid vehicle of ibuprofen were the cause.

\section{Karger'=}




\section{Case Reports in Dermatology}

Case Rep Dermatol 2021;13:154-163

DOI: $10.1159 / 000513469$

(C) 2021 The Author(s). Published by S. Karger AG, Basel www.karger.com/cde

Barootes et al.: Fixed Drug Eruption Treated with Cyclosporine

\section{Discussion and Conclusion}

Outpatient studies estimate that $2.5 \%$ of children who are treated with a drug, and up to $12 \%$ treated with an antibiotic, will experience an adverse cutaneous drug reaction [15-18]. FDEs are thought to account for between 14 and $22 \%$ of cutaneous drug eruptions in children $[1,2]$, but the generalized bullous subtype is rare. Generalized bullous eruptions begin as diffuse, pruritic, well-circumscribed patches, which eventually become oedematous and bullous and involve at least $10 \%$ of the body surface area.

GBFDE is a clinical diagnosis, and given our patient's characteristic history and clinical findings, a biopsy was not performed. Specifically, the presentation before the generalized eruption of dusky red-to-brown oval plaques recurring in the exact same locations within hours of the triggering medication, and resolving with characteristic postinflammatory hyperpigmentation, was pathognomonic of FDE. The generalized eruption lacked mucous membrane involvement and target or target-like lesions and still had the classic oval red-brown plaques from previous exposures reactivating. The diagnosis was even further supported by the patient's history of exposure to non-steroidal anti-inflammatory drugs (NSAIDs), which are well documented as precipitators of GBFDE in the literature [7]. This was confirmed by in vitro toxicity testing.

The exact mechanism of FDE is unknown, but intraepidermal CD8+ memory T cells are thought to play a major role. It is believed that offending drugs bind to basal keratinocytes, resulting in a local inflammatory response. This response upregulates expression of intercellular adhesion molecule-1 (ICAM1) through release of cytokines, which recruits both CD4+ and CD8+ T cells to the site of tissue damage [19]. CD8+ T cells then release cytotoxic perforin and granulysin as well as interferon- $\gamma$ and activate the Fas receptor-Fas ligand system, which results in local apoptosis [19]. Once lesions are clinically resolved, CD8+ T cells remain quiescent in the dermal-epidermal junction. This is responsible for the recurrence of lesions in the same locations if a patient is re-exposed to the offending drug, and may account for findings of in vitro toxicity testing using the patient's lymphocytes [19].

There are many factors which may have influenced the progression of our patient's conventional FDE lesions to the bullous type. Firstly, as reported in the literature, cases of macular FDE may become vesicular or bullous, particularly in patients who continue to receive the drug responsible or consume it in larger doses [20]. In keeping with this, our patient had a history of several preceding episodes of FDE in connection with ibuprofen prior to the bullous FDE. As well, more doses of ibuprofen were reportedly taken prior to her bullous eruption than before the previous episodes. The resultant reactivation of quiescent $\mathrm{T}$ cells from previous episodes, along with activation of additional T cells on this occasion, likely contributed to the increased severity of the eruption and bulla formation. Additionally, the increased severity of this bullous eruption is also demonstrated by the decreasing time interval between drug intake and rash development that the parents reported.

A search of the English-language literature identified a total of 46 studies evaluating FDE in children. A further search (Fig. 3) revealed 21 published cases of the generalized bullous subtype in children [5-9]. Reports of non-generalized bullous eruptions were excluded. The most common drugs associated with GBFDE in children were NSAIDs and antibiotics. Similar 


\section{Case Reports in Dermatology}

Case Rep Dermatol 2021;13:154-163

DOI: 10.1159/000513469

(C) 2021 The Author(s). Published by S. Karger AG, Basel www.karger.com/cde

Barootes et al.: Fixed Drug Eruption Treated with Cyclosporine

to our case, 6 of the paediatric cases reviewed in the literature describe a generalized bullous reaction to NSAIDs. Three others occurred secondary to cotrimoxazole, 3 to hyoscine butylbromide, 2 to sulphadoxine/pyrimethamine, 1 to erythromycin, and 1 to ampicillin. In 5 cases, the exact drug could not be identified [5-9].

The extensive distribution and presence of skin detachment in GBFDE warrants immediate attention and treatment. However, optimal treatment of GBFDE is not yet established due to its rarity and a lack of evidence. Cyclosporine is an immunosuppressive medication that inhibits both CD4+ and CD8+ T-cell activation through dephosphorylation of the nuclear factor of activated T cells (NFAT) and IL-2 production [21]. This then prevents apoptosis by inhibiting both the Fas-ligand pathway and the release of cytotoxic perforin and granzyme. In this case, cyclosporine was initiated due to the patient's rapidly progressive blistering, severe pain, and extensive body surface area involvement (28\%). Cyclosporine was chosen over continuing the prednisone as multiple GBFDE studies have shown that cyclosporine results in rapid cessation of blistering, re-epithelialization of skin, and resolution of lesions with minimal changes in pigmentation $[11,12,14,22]$. Due to its minimal side effects when used acutely and the direct mechanism of inhibiting T-cell activation, it has been suggested to be a therapeutic agent for treating FDE superior to prednisone and intravenous immunoglobulin [11]. As a result, prednisone was stopped after consultation with paediatric dermatology, and oral cyclosporine was commenced at $5 \mathrm{mg} / \mathrm{kg} /$ day divided into 2 daily doses initially.

In the paediatric GBFDE studies that reported treatments, only 2 patients were treated with systemic therapy. One patient received $20 \mathrm{mg}$ /day of prednisone, which was gradually tapered over 1 week. This resulted in resolution of the lesions with postinflammatory hyperpigmentation [5]. Another received $0.5 \mathrm{mg} / \mathrm{kg}$ of prednisone for 1 week, along with supportive management. The lesions stopped progressing within 2 days and subsided completely in 10 days with residual hyperpigmentation and scarring [8]. The other patients received supportive therapy in the form of analgesics, antihistamines, and topical steroid cream.

A further literature search identified 5 adult cases of GBFDE treated with cyclosporine, but no paediatric cases (Table 1) [11-14]. Variable dosages (100 mg/day, $2 \mathrm{mg} / \mathrm{kg} /$ day, or 5 $\mathrm{mg} / \mathrm{kg} /$ day), routes of administration (oral or intravenous), and durations (5-7 days) were used, reflecting both the heterogeneity of institutional and practitioner preferences and the lack of evidence for use in GBFDE. Despite differences in administration, all 5 patients experienced rapid cessation of erythema and complete resolution of their lesions within 7-14 days. While 1 patient had no residual pigmentary change [12], 3 experienced mild postinflammatory hyperpigmentation $[11,13,14]$ and 1 had resultant hypopigmentation [12]. The response in our patient was consistent with the literature, demonstrating significant improvement of the erythema over $24 \mathrm{~h}$ with no further progression of blistering, and then resolution. Most interestingly, resolution occurred with mild postinflammatory hyperpigmentation, which eventually faded. This is significant, as residual hyperpigmentation in FDE is often permanent and disfiguring.

Side effects of cyclosporine include hypertension, hyperlipidaemia, hyperkalaemia, hypomagnesaemia, hypertrichosis, and an increased risk of infections [23]. Rarer, but more serious, side effects are generally seen with prolonged use, and they include hepatotoxicity and nephrotoxicity [23]. None of the 5 adults with GBFDE treated with cyclosporine experienced 


\section{Case Reports in Dermatology}

Case Rep Dermatol 2021;13:154-163

DOI: $10.1159 / 000513469$
(C) 2021 The Author(s). Published by S. Karger AG, Basel www.karger.com/cde

Barootes et al:: Fixed Drug Eruption Treated with Cyclosporine

any adverse effects, which was consistent with our case. Bloodwork including a complete blood count, liver and renal function tests, lipid studies, and electrolytes were monitored prior to and throughout cyclosporine treatment, which did not reveal any abnormalities.

We hereby report the effective and safe use of oral cyclosporine in a rare case of severe paediatric GBFDE. While cyclosporine treatment has been demonstrated to be successful in adult GBFDE cases, to our knowledge, no other studies have evaluated its use in paediatric patients. As such, additional prospective studies are needed to further clarify its role and safety in this population. Studies should also aim to establish the optimal route, dosage, and duration of cyclosporine treatment in children.

\section{Statement of Ethics}

Informed written consent was received by the patient's family for publication of both the case report and the patient photographs. Ethical principles were followed in accordance with the World Medical Association Declaration of Helsinki.

\section{Conflict of Interest Statement}

Each of the authors provides consent for publication and has no conflicts of interest to declare.

\section{Funding Sources}

There is no grant or funding support associated with this article.

\section{Author Contributions}

H.C. Barootes and J.A. Mohammed took lead in writing the manuscript, with input from all other authors. M. Rieder and A. Abuzgaia specifically contributed to explanation of the in vitro toxicity assay. E.R. Peebles and D. Matsui provided critical feedback in shaping the case presentation and discussion.

\section{References}

1 Khaled A, Kharfi M, Ben Hamida M, El Fekih N, El Aidli S, Zeglaoui F, et al. Cutaneous adverse drug reactions in children. A series of 90 cases. Tunis Med. 2012 Jan;90(1):45-50.

2 Sharma VK, Dhar S. Clinical pattern of cutaneous drug eruption among children and adolescents in north India. Pediatr Dermatol. 1995 Jun;12(2):178-83.

3 Segal AR, Doherty KM, Leggott J, Zlotoff B. Cutaneous reactions to drugs in children. Pediatrics. 2007 Oct;120(4):e1082-96. 


\section{Case Reports in Dermatology}

Case Rep Dermatol 2021;13:154-163

DOI: $10.1159 / 000513469$ (c) 2021 The Author(s). Published by S. Karger AG, Basel www.karger.com/cde

Barootes et al.: Fixed Drug Eruption Treated with Cyclosporine

4 Cho YT, Lin JW, Chen YC, Chang CY, Hsiao CH, Chung WH, et al. Generalized bullous fixed drug eruption is distinct from Stevens-Johnson syndrome/toxic epidermal necrolysis by immunohistopathological features. J Am Acad Dermatol. 2014 Mar;70(3):539-48.

5 Sarkar R, Kaur C, Kanwar AJ. Extensive fixed drug eruption to nimesulide with cross-sensitivity to sulfonamides in a child. Pediatr Dermatol. 2002 Nov-Dec;19(6):553-4.

6 Tounkara TM, Baldé H, Soumah MM, Bangoura M, Diané BF, Keita M, et al. Severe cutaneous drug reactions in Guinean children: a monocentric retrospective study of 35 cases. Our Dermatol Online. 2018;9(2):118-22.

7 Kanwar AJ, Bharija SC, Belhaj MS. Fixed drug eruptions in children: a series of 23 cases with provocative tests. Dermatologica. 1986;172(6):315-8.

8 Dogra S, Handa S. Bullous necrotizing fixed drug eruption in an infant. Pediatr Dermatol. 2004 MayJun;21(3):281-2.

9 Mockenhaupt M, Herb T, Liss Y, Bork K, Haustein UF. Generalized bullous fixed drug eruption: analysis of 62 cases. Eur Ann Allergy Clin Immunol. 2010;42(2):43.

10 Cho YT, Chu CY. Treatments for Severe Cutaneous Adverse Reactions. J Immunol Res. 2017;2017:1503709.

11 Malviya N, Cyrus N, Vandergriff T, Mauskar M. Generalized bullous fixed drug eruption treated with cyclosporine. Dermatol Online J. 2017 Feb;23(2):13030/qt5zw8d8vs.

12 Beniwal R, Gupta LK, Khare AK, Mittal A, Mehta S, Balai M. Cyclosporine in Generalized Bullous-Fixed Drug Eruption. Indian J Dermatol. 2018 Sep-Oct;63(5):432-3.

13 Daulatabadkar B, Pande S, Borkar M. Generalized bullous fixed drug reaction: A close similarity to stevensjohnson syndrome. Indian J Drugs Dermatol. 2017;3(1):28.

14 Vargas Mora P, García S, Valenzuela F, Morales C. Generalized bullous fixed drug eruption successfully treatedwith cyclosporine. Dermatol Ther. 2020;33(4):e13492.

15 Ibia EO, Schwartz RH, Wiedermann BL. Antibiotic rashes in children: a survey in a private practice setting. Arch Dermatol. 2000 Jul;136(7):849-54.

16 van der Linden PD, van der Lei J, Vlug AE, Stricker BH. Skin reactions to antibacterial agents in general practice. J Clin Epidemiol. 1998 Aug;51(8):703-8.

17 Cirko-Begović A, Vrhovac B, Bakran I. Intensive monitoring of adverse drug reactions in infants and preschool children. Eur J Clin Pharmacol. 1989;36(1):63-5.

18 Kramer MS, Hutchinson TA, Flegel KM, Naimark L, Contardi R, Leduc DG. Adverse drug reactions in general pediatric outpatients. J Pediatr. 1985 Feb;106(2):305-10.

19 Shiohara T. Fixed drug eruption: pathogenesis and diagnostic tests. Curr Opin Allergy Clin Immunol. 2009 Aug;9(4):316-21.

20 Lisi P, Stingeni L. Fixed drug eruption: bullous form. Clin Dermatol. 1993 Oct-Dec;11(4):461-6.

21 Lee JU, Kim LK, Choi JM. Revisiting the Concept of Targeting NFAT to Control T Cell Immunity and Autoimmune Diseases. Front Immunol. 2018 Nov;9:2747.

22 Daulatabadkar B, Pande S, Borkar M. Generalized bullous fixed drug reaction: a close similarity to StevensJohnson syndrome. Indian J Drugs Dermatol. 2017;3(1):28.

23 Dodd-Butera T, Broderick M. Cyclosporine. Encyclopedia of Toxicology. 3rd ed. Elsevier; 2014. pp. 1114-7. 


\section{Case Reports in Dermatology}
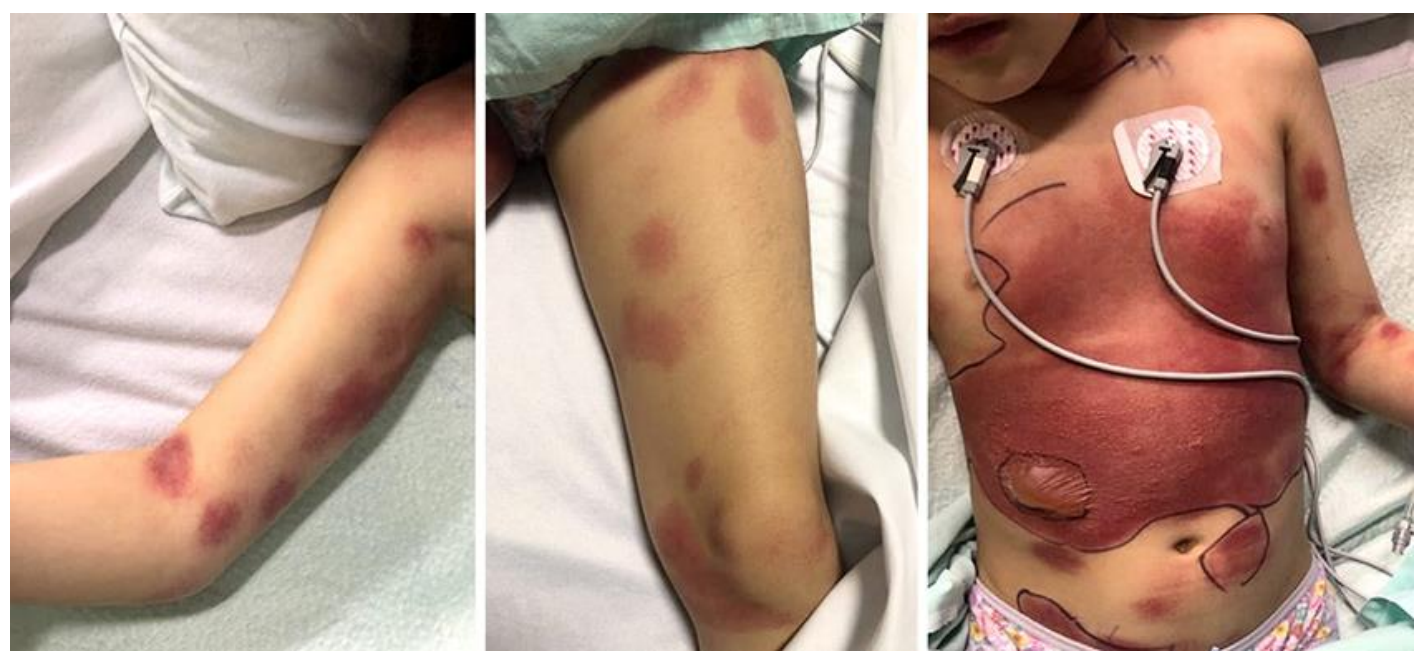

Fig. 1. Oval erythematous-to-violaceous patches and plaques on the right arm (left panel) and left thigh (middle panel), and large erythematous plaques on the abdomen and chest with overlying bulla and vesicles on the right side of the abdomen (right panel).

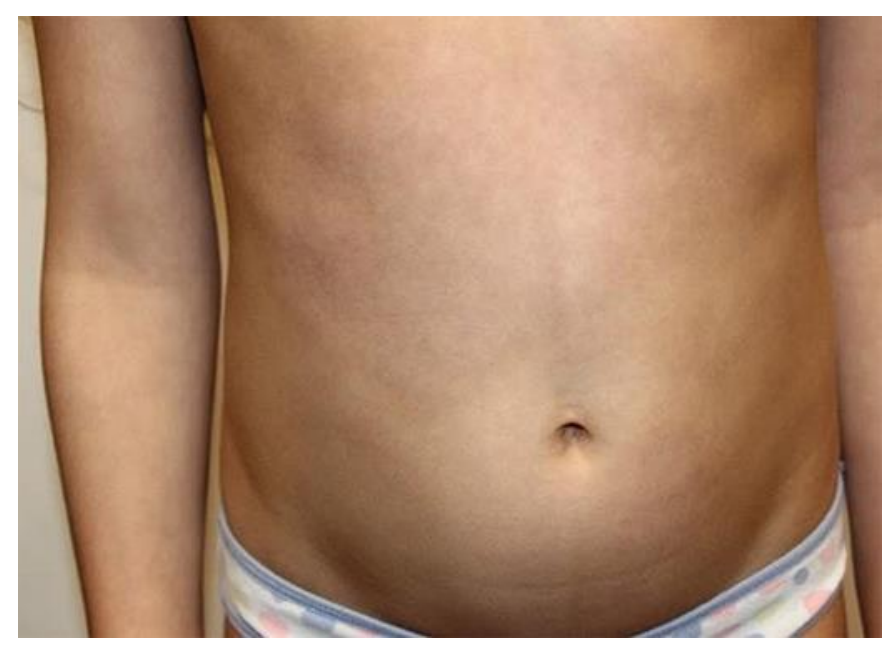

Fig. 2. Abdomen following treatment with cyclosporine $5 \mathrm{mg} / \mathrm{kg} /$ day, weaned over 3 weeks.

\section{Karger'=}


Case Reports
in Dermatology

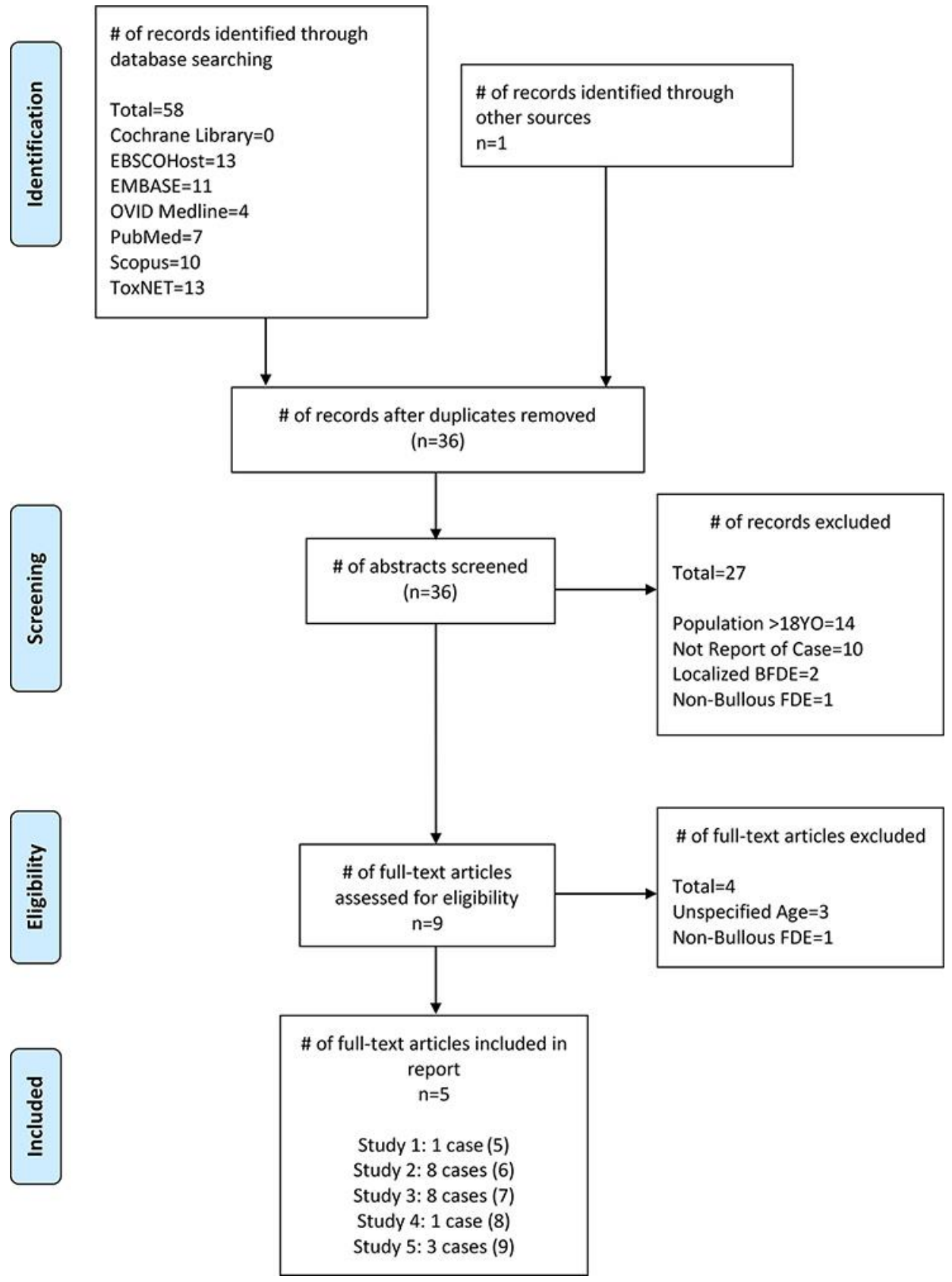

Fig. 3. PRISMA Flow Diagram ${ }^{\circledR}$ of paediatric generalized BFDE cases published in the literature. FDE, fixed drug eruption; BFDE, bullous FDE. 


\section{Case Reports in Dermatology}

\begin{tabular}{l|l}
\hline Case Rep Dermatol 2021;13:154-163 \\
\hline DOI: 10.1159/000513469 & $\begin{array}{l}\text { (c) 2021 The Author(s). Published by S. Karger AG, Basel } \\
\text { www.karger.com/cde }\end{array}$ \\
\hline
\end{tabular}

Barootes et al:: Fixed Drug Eruption Treated with Cyclosporine

Table 1. Summary of 5 published cases of generalized bullous fixed drug eruption in adults treated with a course of cyclosporine

\begin{tabular}{|c|c|c|c|c|c|c|}
\hline $\begin{array}{l}\text { Case } \\
\text { No. }\end{array}$ & Study [Ref.] & $\begin{array}{l}\text { Age at diagno- } \\
\text { sis, years (sex) }\end{array}$ & Route & Dose & Duration & Outcomes \\
\hline 1 & Malviya et al. [11] & 40 (male) & Intravenous & $\begin{array}{l}3 \mathrm{mg} / \mathrm{kg} / \text { day in } \\
2 \text { divided doses }\end{array}$ & 5 days & $\begin{array}{l}\text { Improvement of all lesions within } 48 \mathrm{~h} \\
\text { Reduction of erythema and pain } \\
\text { Dusky centres failed to progress } \\
\text { Resultant hyperpigmentation at prior sites }\end{array}$ \\
\hline 2 & Beniwal et al. [12] & 42 (male) & Unspecified & $5 \mathrm{mg} / \mathrm{kg} /$ day & Unspecified & $\begin{array}{l}\text { Complete healing of lesions within } \\
1 \text { week } \\
\text { No pigmentary change }\end{array}$ \\
\hline 3 & Beniwal et al. [12] & 24 (male) & Unspecified & $5 \mathrm{mg} / \mathrm{kg} /$ day & Unspecified & $\begin{array}{l}\text { Excellent response in 5-7 days } \\
\text { Lesions healed with hypopigmentation }\end{array}$ \\
\hline 4 & Daulatabadkar et al. [13] & 55 (male) & Oral & 100 mg per day & 7 days & $\begin{array}{l}\text { After } 14 \text { days, patient recovered } \\
\text { completely without any sequalae } \\
\text { Complete re-epithelialization of skin } \\
\text { Lesions healed with mild } \\
\text { hyperpigmentation }\end{array}$ \\
\hline 5 & Vargas Mora et al. [14] & 35 (female) & Oral & $5 \mathrm{mg} / \mathrm{kg} /$ day & 5 days & $\begin{array}{l}\text { Cessation of blistering } \\
\text { Lesions resolved with } \\
\text { postinflammatory hyperpigmentation }\end{array}$ \\
\hline
\end{tabular}

